\title{
O TRABALHO POR TRÁS DOS RESULTADOS: OS GRUPOS UNIVERSITÁRIOS DE PESQUISA E EXTENSÃO
}

\section{The work behind the results: university research and extension teams}

\section{El trabajo que hay detrás de los resultados: los equipos de pesquisa y de extension}

\author{
Olga Maria Panhoca da Silva ${ }^{1}$ \\ Mario Cesar Nascimento ${ }^{2}$ \\ Celeste Martina Skewes Guerra ${ }^{3}$
}

\begin{abstract}
RESUMO
Assumindo o trabalho de pesquisa como indissociável da extensão e do ensino, este artigo apresenta, sem a pretensão de ser exaustivo, algumas sugestões para a reflexão sobre o trabalho de investigações científicas em populações ou comunidades. Todo o discurso sobre o trabalho ocorrerá dentro de discussões metodológicas e através de vivências do método científico. Os resultados das investigações costumam ser mais fáceis de serem divulgados e apresentados do que o seu método ou o trabalho de sua equipe geradora. Neste artigo enfatizamos que o "pulo do gato" de uma investigação está no envolvimento do grupo na construção do método do trabalho. A pesquisa e a extensão dependem do grupo e o sucesso repousa no empenho e nas habilidades do grupo. Sempre o método deve levar em conta o tempo e os recursos que se têm ao alcance, e um dos recursos fundamentais é a equipe de trabalho. A coordenação e a supervisão são integrantes do grupo e conduzem o trabalho. Por fim, a compensação não está somente nos resultados da investigação, mas também no prazer de se ver pessoas diferentes se tornarem uma equipe em torno de um trabalho, mas este não pode ultrapassar a tênue linha do respeito à pessoa e o respeito à verdade.

Palavras-Chave: trabalho. grupos de pesquisa e extensão. método científico.
\end{abstract}

\begin{abstract}
Based on the idea that is impossible unlinking the research' work from the extension' work. This paper presents, without pretention of finish the issue, some suggestions to reflect about Scientifics' investigations in communities and population. The assumption about this will occurs by insights of the scientific methodologies' point of views and supported by the authors expertise. The results of the investigations are usually easier to publish than the method and the team work. In this paper we hard believe that the "right way" to do good investigation is the commitment of the team in to build the methods' work. The success of research and the extension team is the result of their dedication and abilities. First of all, to conclude the investigation, the method needs attention on time and resources. The coordinator and supervisors are important part of this team and conduct the tasks and works. To finish, the pleasure in one investigation is not only the results but to work with people that became a team, however, the big challenger of this kind of work is to stay on the light line of the respect and the truth.

Keywords: work. research and extension' teams. scientific method.
\end{abstract}

1 Pós-doutora pela Faculdade de Saúde Pública da Universidade de São Paulo. Professora Adjunta da Universidade do Estado de Santa Catarina - UDESC. E-mail: ompanhocas@yahoo.com.br

2 Mestre pela Universidade do Estado de Santa Catarina - UDESC. Diretor de Extensão do Centro de Ciências da Saúde e do Esporte da UDESC.

3 Graduanda de Jornalismo da Universidade Austral do Chile - UACH fazendo intercâmbio na ITCP/UFPR. 


\section{RESUMEN}

Asumiendo el trabajo de investigación como indisociable de la extensión y educación, este artículo presenta, sin la pretensión de ser exhaustivo, algunas sugerencias para la reflexión sobre el trabajo de investigaciones científicas en poblaciones o comunidades. El trabajo se centra en las discusiones metodológicas y las experiencias a través de método científico. Los resultados de las investigaciones son más facilmente divulgados y presentados de lo que es su método o el trabajo de su equipo generador. En este artículo enfatizamos que la clave de una investigación está en el desarrollo del grupo en lo que refiere a la construcción del método de trabajo. La investigación y la extensión dependen del grupo y el éxito reposa en el empeño y en las habilidades del grupo. Siempre el método debe tener en cuenta el tiempo y los recursos que se tienen al alcance, y uno de los recursos fundamentales es el equipo de trabajo. La coordinación y la supervisión son integrantes del grupo y conducen el trabajo. Finalmente la compensación no está solamente en los resultados de la investigación, pero también en el placer de ver personas diferentes tornarse un equipo en torno a un trabajo, sin embargo esto no puede pasar la delgada línea del respeto hacia a la persona y el respeto a la verdad.

Palabras Claves: trabajo. equipos de investigación y extensión. métodos científicos.

\section{Agradecimentos}

Agradecemos a todos os que partilharam conosco os trabalhos em grupo. Sabemos que todos esses cuidados afastaram algumas pessoas, mas temos a certeza de que aqueles que permaneceram trabalhando podem se orgulhar dos resultados verdadeiros de suas investigações.
Apresentação

Este artigo parte da experiência dos autores em atuar no trabalho de pesquisa $e$ extensão universitária. Muito desse aprendizado ocorreu fora dos caminhos convencionais e através da vivência de longos anos de atuação nesses grupos. A princípio costumava-se separar o trabalho de extensão da pesquisa, como trabalhos distintos, mas, para nossa felicidade, as universidades estão agora deixando essa antiga concepção de lado (FÓRUM DE PRÓ-REITORES DE EXTENSÃO DAS UNIVERSIDADES PÚBLICAS BRASILEIRAS, 2006; DIAS SOBRINHO, 2002) e assumindo o trabalho de pesquisa como indissociável da extensão $e$ do ensino. Partindo dessa concepção oferece, sem a pretensão de ser exaustivo, algumas sugestões para a reflexão sobre o trabalho de pesquisa $e$ extensão que atuam com populações ou comunidades.

Usaremos preferencialmente a palavra investigação em substituição à palavra, usualmente consagrada, pesquisa. Esta será usada para caracterizar e enfatizar que as buscas por conhecimento não são uma atividade exclusiva de grupos de pesquisa, mas são parte do trabalho acadêmico e cientifico. Ressaltamos também que todo o discurso sobre o trabalho ocorrerá dentro de discussões metodológicas, ou melhor, se darão através de vivências do método científico. Acreditamos que:

\footnotetext{
"O método é a atividade pensante do sujeito.

Assim, o método torna-se central e vital: Quando há, necessária e ativamente, reconhecimento e presença de um sujeito procurante, conhecente, pensante; Quando a experiência não é uma fonte clara, não equivoca do conhecimento; Quando se sabe que o conhecimento não é a acumulação dos dados ou informações, mas sua organização; $[\ldots]$
} 
Quando o conhecimento revela e faz renascer ignorâncias e interrogações. (MORIN, 2002, p. 337-8).

Este ensaio versa sobre o trabalho de grupos de pesquisa e extensão que acreditam no livre arbítrio das pessoas e que entendam a ciência, a pesquisa e a extensão como um bem coletivo, construído com informações cuidadosamente investigadas. Acrescenta-se a isso que a construção do saber passa pelo aprendizado coletivo, não seletivo, e pelo crescimento e enriquecimento de todos os envolvidos no grupo de trabalho (FREIRE, 1983).

Os grupos de pesquisa e extensão que atuam com populações ou comunidades deveriam se configurar como um conjunto aberto de pessoas que partilham o interesse em estudar os fenômenos da vida humana a partir de uma visão transdisciplinar (FÓRUM DE PRÓ-REITORES DE EXTENSÃO DAS UNIVERSIDADES PÚBLICAS BRASILEIRAS, 2006). Essa transdisciplinaridade se justifica pela complexidade do campo de atuação. O que torna o trabalho desse tipo de grupo interessante é a diversidade de opções de atuação e de visões do mundo que um grupo transdisciplinar pode oferecer. A troca interna do grupo torna qualquer assunto ou tema ampliado e diversificado de acordo com as formações e interesses de cada membro do grupo.

Quando se trata de inquéritos para estimativas que subsidiem o planejamento $e$ a avaliação de fenômenos populacionais e ou de grupos humanos, a fidelidade dos dados coletados passa a ser de máxima importância, uma vez que esses dados se transformarão em informações de base que sustentarão decisões.

Além disso, os agrupamentos humanos, por mais óbvio que possa parecer, são compostos por pessoas, e estas devem ser tratadas como dignas de todo o cuidado, respeito e recato, além de serem merecedoras do direito de livre arbítrio (FREIRE, 1983). Qualquer interferência que se faz nessas comunidades está, no mínimo, toman- do o tempo das pessoas e lançando-as a assuntos que talvez elas não estivessem contatando por sua espontânea vontade, isto é, toda vez que questionamos uma pessoa estamos interferindo no mundo dela (MORIN, 2002). Devemos ser críticos e curiosos para buscar a atitude científica (CHAUÍ, 2004). Decorrendo dessa visão, portanto, temos que saber muito bem se vale a pena perguntar e interferir e se o objetivo do questionamento justifica essa ação. Importunar as pessoas não é papel da universidade.

Os resultados das investigações são normalmente mais fáceis de serem divulgados e apresentados do que o seu método ou o trabalho de sua equipe geradora, mas afirmamos enfaticamente que o "pulo do gato" de uma investigação está no envolvimento do grupo na construção do método do trabalho.

\section{O trabalho inicial: configurar o grupo}

A pesquisa e a extensão dependem do grupo. O sucesso repousa no empenho e nas habilidades do grupo, muito mais do que isso, está no interesse em perseguir um objetivo, que deve ser o mesmo para todos, apesar de cada um ter a sua tarefa e a sua meta.

Embora exista uma liderança normalmente dada pelo professor mais experiente, a intenção de um grupo de trabalho deve ser a partilha de conhecimento, e não a concentração deste para o enriquecimento intelectual de um subgrupo específico ou de um líder.

Os grupos de pesquisa e extensão devem ser geridos para que todos aprendam, respeitando cada membro em suas peculiaridades $e$ afinidades. Esse balizamento é um dos grandes desafios desse tipo de trabalho. A abertura da informação e a ajuda mútua devem transpassar as barreiras dos cargos e vaidades pessoais.

Um grupo de trabalho acadêmico, como todo grupo, surge de nossa população, formada a partir de diversas etnias e com valores e culturas diferentes entre si, apesar de compartilharem a convivência acadêmica, formar padrões 
rígidos normalmente não é a solução ideal. A vida acadêmica lida com pessoas niveladas do ponto de vista da oportunidade de escolaridade, mas conviverá com diferentes personalidades e caráter, sendo necessário um líder forte que seja ouvido como tal, no entanto, que não apague essas diversidades através de imposições. Em situações de diferenças, a liberdade é uma boa tática, mas a liberdade de trabalho exige conhecimento, foco, acompanhamento e supervisão.

A diferenciação entre a população rural e urbana, e entre a população litorânea $e$ a interiorana pode representar uma dificuldade para obter a compreensão de metas e objetivos, portanto, dificuldades em resultados favoráveis. Para uma equipe coesa deve-se incentivar a solidariedade e a troca de experiências. O vocabulário, os costumes e ações vão moldando as pessoas e formando laços que transformarão o grupo de pessoas em uma equipe integrada. Para enfrentar esse quadro é necessário entender o que está acontecendo e levar os comportamentos equivocados para caminhos mais adequados de cooperação e respeito.

O objetivo da investigação deve, preferencialmente, surgir em discussões sobre temas ou problemas estudados, mas, quando não forem espontâneos, uma série de estudos deve ser feita sobre eles para que todos se apropriem do universo que circunda esse objetivo: dividam as suas dúvidas e fiquem motivados em conhecer realmente o problema em questão.

Esses propósitos partem do trabalho em grupo e do encontro dos participantes do grupo que deve dar-se num ambiente de tranquilidade e bem-estar. As funções e atividades, assim como esse clima, podem fixar a equipe no seu ambiente, diminuindo assim o abandono $e$ evasão de membros. Uma vez iniciada a investigação, cada pessoa que evade se torna insubstituível, pois não existe reposição de vivências e partilhas em trabalhos coletivos.

A principal questão deve ser sempre a proposição da investigação e seu objetivo.
Desvendar esse universo pelo trabalho deve ser um valor e um bem comum. O tema e o problema devem ser sempre partilhados. O objetivo geral deve ser inesquecível para todos, mas os objetivos específicos podem ser administrados pelas afinidades de cada pessoa, dividindo os membros da equipe em subgrupos ou em tarefas.

Para facilitar o trabalho em um grupo inexperiente pode-se pensar em etapas a serem cumpridas:

- Uma introdução ou um panorama da problemática; quando pertinente, a localização geográfica onde se insere a população a ser estudada, cultura, valores e modo de vida.

- Esclarecimento do objetivo da investigação e o seu relacionamento com cada um dos objetivos específicos;

- Descrição dos métodos possíveis, estudo das possibilidades e das escolhas;

- Descrição do processo e da operacionalização da investigação;

- Delineamento da investigação: partilhamento das tarefas e configuração do cronograma;

- Atribuição de encontros e datas para cada etapa de atividades.

A partir dos objetivos se estabelece as informações desejadas, e partindo do que se deseja em termos de informações é que se deve buscar o método de investigação.

O método deve levar em conta o tempo e os recursos que se têm ao alcance. Um dos recursos fundamentais é a equipe de trabalho $e$ dentro dela a equipe de campo. Para esse recurso este artigo tem mais propriedade.

Coletar dados, compilá-los, analisá-los e responder ao objetivo não é tarefa fácil para uma equipe de trabalho. Subequipes poderão ser formadas para cada uma das tarefas desde que as dificuldades e os resultados de cada fase sejam compartilhados por toda a equipe.

Extensão em Foco, Curitiba, n. 7, p. 43-53, jan./jun. 2011. Editora UFPR 
Cuidados no trabalho: lidando com as pessoas

Atualmente muitos inquéritos que coletam dados populacionais já se encontram disponíveis, seja tanto na literatura nacional como na internacional. Esses modelos prontos normalmente já vêm validados, o que facilita muito e também reduz o tempo gasto nesta etapa, mas quando os modelos não são de domínio público uma autorização documental deve ser solicitada ao autor (FLECK, 1999), este é quem autoriza o uso.

Nas traduções de questionários internacionais ou não elaboração de questionários inéditos, o cuidado com a intenção da pergunta deve ser cautelosamente interpretada (ROCHA; FLECK, 2009). Isso deve ser feito partindo da verificação da intenção do dado. Coisas simples, como uma palavra, podem levar a interpretações equivocadas que inviabilizarão a análise. Um exemplo disto é quando se pergunta o estado civil de uma pessoa: a intenção é saber se a pessoa vive em união conjugal com alguém, se compartilha o domicílio com um parceiro, se há compartilhamento nas responsabilidades $e$ cuidados com a prole, se costuma ter relações sexuais ou somente deseja conhecer a situação legal do entrevistado? Estas e muitas outras visões podem ser interpretadas pelo respondente e esta pessoa responderá segundo o seu entendimento. Quanto mais clara e óbvia for a pergunta, mais focada será a resposta e melhor qualidade terá o dado. Para isso, toda a equipe deve conhecer qual a informação que se pretende em cada uma das questões que serão feitas ao entrevistado e isso demanda tempo, estudo e compartilhamento do trabalho.

Os questionários devem levar em conta o informante, a qualidade de seu conhecimento, o tempo disponível para as respostas e o local aonde ocorrerá a aplicação. Muitas vezes a idade e o gênero do entrevistado influem na propriedade resposta. Identificar o entrevistado de uma maneira homogênea também é parte do treinamento para o trabalho de campo, assim como saber exatamente quem poderá e quem não poderá responder as perguntas.

Para se controlar a qualidade, o trabalho de campo deve contar com: mapeamento da área com treinamento adequado em território ou área geográfica da atuação dos entrevistadores, mapeamento dos domicílios a serem entrevistados no território ou identificação dos domicílios $e$, preferencialmente, contato prévio com os moradores e elaboração do banco de dados de endereços. Todo este processo é recomendado antes do início das entrevistas e proporcionará segurança para a equipe conduzir essa fase de trabalho.

A escolha da equipe de entrevistadores deve ter critérios, no caso de grupos de pesquisa e extensão a participação no grupo é fundamental. Com este critério, consegue-se obter uma equipe responsável, motivada e engajada com o trabalho e com os objetivos do estudo, facilitando muito o processo de supervisão.

Toda a equipe que sai a campo deve estar identificada, preferencialmente, com um uniforme ou um jaleco ou pelo menos um crachá, demonstrando a seriedade do trabalho, assim como para estabelecer maiores vínculos de confiança entre os pesquisadores e os entrevistados. Um líder ou coordenador cuida de seu grupo facilitando a sua atuação e proporcionando-lhes segurança e bem-estar.

A melhor equipe para o trabalho de pesquisa é a de extensão, e a melhor equipe para o trabalho de extensão é a de pesquisa, uma vez que a pesquisa requer um aluno que saiba atuar junto à comunidade facilitando a operacionalização do trabalho em campo e, por outro lado, a extensão requer um aluno que se concentre focando um objetivo para não se perder durante a atuação em campo.

Preparando a equipe para o trabalho de campo: um por todos e todos por um

Para não se perder em um mar de entrevistas deve ser criada uma estrutura de 
recursos humanos composta por coordenador, supervisores e entrevistadores. Essa equipe estruturada garante que o trabalho seja executado dentro do prazo previsto, garante suporte técnico e científico para a base de trabalho, isto é, para os entrevistadores, e respostas às dúvidas que possam talvez surgir durante o processo de coleta. Para sanar essas dificuldades não existe norma fixa encontrada na literatura, a "lógica em uso", segundo Popper (1993), deve ser aplicada imediatamente. Tal expressão mostra que na epistemologia da ciência os imprevistos e situações inéditas são esperados e devem ser respondidas ou contornadas. Para isso essa hierarquização de equipe de trabalho deve ter um fluxo permanente e confiante de troca de informações. Uma vez surgido o imprevisto ou a dúvida em campo, o coordenador deve responder, decidir e anotar em um diário de campo tanto a dúvida quanto a decisão para comunicá-la a toda a equipe, garantindo assim a uniformidade de visão $e$ condução única do trabalho.

A investigação científica nasce e está cercada de incertezas, mas, longe de afastar o grupo, isto deve ser um tema a ser permanentemente discutido (PEREIRA, 2001). É sempre melhor a incerteza do que a certeza, pois na primeira se pode buscar mais conhecimento $e$ na segunda não há questionamento. A resposta do supervisor não necessariamente deve ser buscada exclusivamente por ele, o problema pode ser partilhado com toda ou parte da equipe e a opção de conduta pode partir de deliberações coletivas.

Inicialmente os entrevistadores que não têm experiência prévia devem ser treinados dentro da equipe, os mais tímidos e retraídos devem adquirir confiança e postura segura, assim como os mais extrovertidos devem adquirir uma postura mais contida e respeitosa. Com isso, pode-se manter uma uniformidade de posturas entre os entrevistadores. Não se pode partir do ponto de vista de que todos os entrevistadores são iguais, pois as pessoas têm características próprias $e$ peculiares $e$, portanto, devem ser treinadas $e$ estimuladas para superar as suas restrições.

Ainda pode ocorrer a necessidade de treinamentos específicos sendo assim, se pode lançar mão de um perito externo ao grupo, que faça o treinamento e a calibração da equipe (LANDIS JUNIOR; KOCH, 1977) para que esta se torne apta à ação. Por exemplo: para a mensuração da cintura e do quadril das pessoas se deve fazer um treinamento específico para que essas medidas sejam tomadas de um modo correto e recomendado por especialistas da área, o mesmo ocorre com a pressão arterial, medidas de perímetro encefálico, coordenação motora $e$ outros quesitos.

Alguns fenômenos podem ser mensurados por diversos métodos e neste caso um estudo prévio deve esclarecer à equipe qual método escolher. A disponibilidade do treinamento é um dos quesitos que deverão ser levados em consideração nessa hora. Essas opções devem ficar claras para toda a equipe e para os leitores dos resultados.

O pré-teste do instrumento de trabalho ou do questionário deve sempre ser feito em uma parcela de pessoas que não pertençam à amostra da investigação, ou seja, pessoas semelhantes nas características dos entrevistados, mas que não tenham contato com estes. Este cuidado garante uma uniformidade de respostas sem prévia exposição ao conteúdo, ou seja, todos os entrevistados devem entrar em contato com a entrevista sem tempo anterior para elaborarem suas respostas ou discutirem outras opiniões, a fim de responderem a "sua verdade imediata".

A tecnologia usada durante a investigação deve ser apropriada. No caso de inquéritos populacionais, os entrevistadores devem ser treinados e os equipamentos calibrados (WHO, 1995; 1997). Isso inclui as anotações e o uso de laptops, geoprocessadores, balanças e outros itens de baixa tecnologia como fita métrica e escala de cores. Cada investigação tem fenômenos próprios a serem explorados e, 
consequentemente, uma determinada tecnologia envolvida nessas mensurações, portanto, a equipe de trabalho deve ser dominadora destas técnicas e seus conhecimentos específicos para formar o método.

Os supervisores e coordenadores das equipes devem auferir todos os instrumentos de medição antes de utilizá-los em campo, garantindo assim a homogeneidade do dado.

Outra fase do trabalho de campo é o treinamento dos entrevistadores, enfatizando a postura ética que deve ser mantida durante as entrevistas, incluindo roupas adequadas $e$ respeito à privacidade.

Em algumas situações especificas, o gênero do entrevistador pode interferir na resposta do entrevistado (OLIVEIRA, 2004; VILLAR, 2007), então uma adequação da equipe de entrevistadores deve ser organizada para solucionar este problema. Em caso de dúvida sobre essa interferência um pré-teste deve ser feito e os dados devem ser comparados estatisticamente para apurar diferenças.

Como já dito, para se assegurar a qualidade da investigação é necessário se assegurar a boa qualidade dos dados, essa segurança deixar o líder tranquilo com a mesma, calculando amostras mínimas (SZWARCWALD; DAMACENA, 2008). As variáveis estudadas devem ser mensuradas através de padrões claros para facilitar o processo de análise. A escolha das medidas das variáveis depende do conhecimento que se tem da variação do objeto, da tecnologia que se usa na mensuração e na habilidade do observador para reconhecer a medida.

Para se evitar a variação nas medições ou erro na mensuração que podem ocorrer devido aos diferentes entrevistadores, treina-se a equipe de trabalho com padrões. Por vezes podem ocorrer diferenças de mensuração ou diagnóstico entre os examinadores (erros entre examinadores), ou diferenças de mensuração ou diagnóstico realizado por um examinador em diferentes momentos (erros intraexaminador).
Alguma variação sempre acontece e é chamada de erro aleatório.

Para se controlar os erros, são adotadas técnicas para melhorar a acurácia $e$ a precisão dos dados. Para saber se o observador está medindo o que deve ser medido, ou seja, a acurácia, é feito um treinamento adequado a cada situação que possivelmente seria encontrada em campo. A reprodutibilidade ou variabilidade das medidas de cada entrevistador são comparadas com um "padrão ouro de medidas", então, com os valores obtidos se calcula a variação dentre elas e o "padrão ouro" garantindo a precisão. Cada entrevistador repete sucessivamente a mensuração até que ele consiga um valor igual ao padrão estabelecido, ou seja, variação inexistente aceitável (FLETCHER et al., 1996; PEREIRA, 2001).

A padronização de critérios muitas vezes é desrespeitada frente à pressa na obtenção das informações e na conclusão das investigações. Consequentemente, as informações obtidas não são verdadeiras e os resultados possivelmente estarão equivocados.

A calibração dos examinadores é então feita através da repetição das mensurações nas mesmas pessoas pelos mesmos examinadores, ou pelo mesmo examinador em tempos diferentes (WHO, 1997, 1995). A calibração deve assegurar a uniformidade de interpretação, entendimento e aplicação dos critérios das várias condições a serem observadas e registradas. Deve-se assegurar que cada examinador siga o padrão adotado e minimizar variações nos erros "intra" e "entre" diferentes examinadores (WHO, 1997).

Outro item importante no treinamento da equipe de trabalho consiste na desinibição dos entrevistadores em se aproximar dos entrevistados e solicitar que eles permitam as mensurações. Essa superação é conseguida com treinamento dentro da própria equipe. Este exercício faz com que todos adquiram confiança $e$ naturalidade no procedimento da mensuração $e$ 
na abordagem das pessoas, assim como fortalece a coesão da equipe.

Segue um exemplo do que foi exposto acima: este exemplo versa sobre um inquérito domiciliar com base populacional, sendo que um dos módulos do questionário abordava a violência doméstica entre casais com união estável e que residiam no mesmo domicílio.

TABELA 1 - CONCORDÂNCIA ENTRE AS DUPLAS DE ENTREVISTADORES DURANTE O TREINAMENTO.

\begin{tabular}{cccc}
\hline $\begin{array}{c}\text { Dupla de entrevista- } \\
\text { dores }\end{array}$ & Teste de Kappa & $\begin{array}{c}\text { Replicabilidade se- } \\
\text { gundo BIRT }\end{array}$ & p unilateral \\
\hline 1 & 0,6250 & Boa & $\mathrm{p}<0,0001$ \\
2 & 0,6250 & Boa & $\mathrm{p}<0,0001$ \\
3 & 0,6087 & Boa & $\mathrm{p}<0,0001$ \\
4 & 0,8011 & Muito boa & $\mathrm{p}<0,0001$ \\
5 & 0,7857 & Boa & $\mathrm{p}<0,0001$ \\
6 & 0,4706 & Regular & $\mathrm{p}=0,0021$ \\
7 & - & Perfeita & \\
8 & - & Perfeita & \\
9 & - & Perfeita & \\
\hline
\end{tabular}

No exemplo, os homens e as mulheres eram entrevistados ao mesmo tempo em locais diferentes e respondiam as mesmas questões. Na ocasião se suspeitou que as agressões não fossem relatadas do mesmo modo frente ao entrevistador do sexo masculino em relação ao feminino. Então foi feito um pré-teste específico para averiguar esse fato, visto que existem diferenças entre os comportamentos masculinos e femininos, e considerando que esta desigualdade pode ser compreendida por receio ou medo do entrevistado revelar a verdade.

Além dessa dúvida também este módulo sobre violência foi considerado pelos entrevistadores como o mais constrangedor para ser aplicado, então, foi reforçada a necessidade de um treinamento específico e detalhado. $\mathrm{O}$ coordenador do treinamento formou duplas de entrevistadores sendo um homem e uma mulher, com idades semelhantes para aplicar a entrevista em nove pessoas como pré-teste. Os nove convidados foram entrevistados individualmente pela dupla em momentos distintos, mas no mesmo dia. O entrevistado era inquirido por um membro da dupla e depois de em torno de uma hora era novamente inquirido pelo outro membro da dupla. As respostas eram passadas em uma planilha que comparava as respostas entre os membros da dupla.

Foi realizada a verificação das respostas através do teste de Kappa (LANDIS, 1977) ilustrado abaixo, na tabela 1. Cada dupla de entrevistadores recebeu um número para identificação na tabela abaixo e a concordância de respostas foi avaliada.

O teste acima descrito comparou a proporção das concordâncias entre os membros das duplas observadas na mesma variável. Apesar do exemplo acima tratar de um estudo quantitativo, não se deve excluir os fatores que influenciam as respostas, como por exemplo, a representação social de gênero.

Após a conclusão do pré-teste, foram verificadas as divergências ocorridas. Nas matrizes podem-se comparar as divergências $e$ concordâncias e permitir a realização do teste considerando-se todos os critérios em conjunto, e também para cada um dos itens separadamente. É importante ressaltar que a comparação e discussão dos resultados através do uso das matrizes é um elemento importante nesta fase do treinamento, sendo o cálculo do teste estatístico secundário e complementar à vivência.

A matriz permite identificar os quesitos nos quais os examinadores tiveram maior dificuldade de fixação, enquanto que o resultado do teste Kappa não fornece essa informação. A discussão destes resultados, matriz e teste estatístico, facilita ao grupo a ideia de atingir uma 
boa concordância antes do início do trabalho de campo.

Os artigos e relatórios de estudos que não adotam padronização e não medem reprodutibilidade entre os examinadores, podem estar apresentando distorções da realidade em dois sentidos, na concordância de medidas entre os examinadores e na distância entre os valores aferidos por estes e o valor presumidamente verdadeiro.

Os digitadores devem também receber um treinamento antes do início das digitações dos questionários, para conhecerem a sistematização do armazenamento dos dados, bem como terem segurança e clareza nas codificações necessárias para o entendimento das informações. Eles devem participar da investigação, ou pelo menos serem situados sobre a importância da digitação consciente, assim como da importância do trabalho de investigação. Esse treinamento facilita a compreensão da complexidade da investigação.

O que mais impressiona nesta fase é a aproximação de pensamento $e$ ações entre as pessoas e o grupo como um todo, podendo-se vislumbrar o pensamento de Edgar Morin quando discorre sobre como o todo contém a parte, a parte também contém o todo, sendo que o todo é mais do que a soma das partes e a parte é mais dos que uma fração do todo que a contém e não contém (MORIN, 2002).

O trabalho dos supervisores: conduzindo a unidade e a qualidade

A coordenação $e$ a supervisão dão o compasso do trabalho. Eles devem atuar como integrantes do grupo, mas ao mesmo tempo conduzir o trabalho. Os supervisores atuam na entrevista verificando a postura dos entrevistadores $e$ as respostas e as não respostas. Em momentos demarcados, a equipe se reuniu para discutir as dificuldades de modo geral, tanto no acesso, como na abordagem ou nos quesitos da entrevista. Essas discussões e esclarecimentos são mais necessários no início do trabalho de campo quando a maioria dos imprevistos ocorre. A supervisão sempre deve verificar os questionários quanto ao preenchimento e repetir algumas entrevistas ou partes de entrevistas para verificar a qualidade do dado.

Para garantir o controle de qualidade das entrevistas e digitação, deve ser realizada conferência paralela, ou seja, os entrevistadores realizam o trabalho em grupos de duas ou três pessoas e os digitadores em duplas. Esse cuidado tem a tripla finalidade de preservar a segurança do entrevistador em campo para que este não se exponha sozinho, verificar coletivamente a qualidade da entrevista e minimizar o cansaço durante o trabalho.

Os supervisores de entrevista realizam a conferência da resposta de algumas variáveis chaves, e quando surgem dúvidas, o entrevistador do domicílio deve ser consultado.

Para se assegurar o preenchimento $e$ adequação dos questionários são recomendadas as seguintes etapas:

- Conferência entre os entrevistadores no ato do término da entrevista;

- Revisões e verificação do preenchimento adequado pelo supervisor;

- Codificação para o armazenamento.

Em caso de dúvidas residuais, retorna-se aos domicílios e refaz-se a entrevista.

Todo o processo de digitação deve ser acompanhado por um supervisor, e este deve fazer a triagem das incoerências dos dados $e$, se for o caso, realizar a unificação dos bancos digitados.

Os aspectos éticos do trabalho de campo: o livre arbítrio e o respeito

As investigações que envolvem seres humanos ou suas informações indiretas devem ser aprovadas pelos Comitês de Ética em Pesquisa. Não só os experimentos são alvo desses comitês, uma simples entrevista pode interferir na vida de uma pessoa e, portanto, deve ser avalia- 
da e aprovada por uma comissão (CONSELHO NACIONAL DE SAÚDE, 1996).

Durante o trabalho de campo deve ser mantida a privacidade dos entrevistados garantindo a participação anônima e voluntária. Sempre um Termo de Consentimento Livre e Esclarecido deve ser entregue a cada pessoa entrevistada antes do início das perguntas. Os entrevistados devem assinar os termos como uma condição necessária para a participação no estudo. No caso dos menores de 18 anos e dos incapazes, um responsável ou tutor deve assinar autorizando a intervenção. Nessa assinatura todos os participantes recebem um termo com o resumo das intenções do estudo e seus objetivos, assim como a identificação dos responsáveis e seus contatos para esclarecimento. Sempre os critérios da investigação e do trabalho de campo são autorizados pelos Comitês de Ética em Pesquisa em Seres Humanos.

Após as entrevistas os questionários recebem uma identificação codificada, usualmente numérica, e são armazenados de acordo com a lógica estabelecida no método. Cada pessoa entrevistada recebe uma numeração para manter sigilo e a privacidade das informações, respeitando as questões éticas que envolveram a pesquisa. A partir da entrega do questionário ao supervisor, apenas a identificação numérica passa a vigorar.

\section{Considerações finais}

O trabalho com comunidades, professores, técnicos e alunos sempre será um grande desafio. Os fenômenos da vida humana, por sua complexidade, jamais serão elucidados completamente $e$ as pessoas que se lançam nessa tarefa são sempre obstinados sonhadores. A compensação desse desafio sem fim é o prazer de se ver pessoas diferentes se tornarem uma equipe em torno de um trabalho numa busca contínua, mas o trabalho não pode ultrapassar a tênue linha do respeito à pessoa e o respeito à verdade. Este artigo teve a intenção de mostrar alguns modos de se tentar conseguir esse feito.

\section{REFERÊNCIAS}

BRASIL. Resolução n. 196. Brasília, DF: Ministério da Saúde. Conselho Nacional de Saúde, 1996. Disponível em: <http://www.datasus.gov.br/conselho/resol96/ RES19696.htm>. Acesso em: 01/2011.

CHAUÍ, M. S. Convite à filosofia. 13 ed. São Paulo: Ática, 2004. $424 \mathrm{p}$.

DIAS SOBRINHO, J. Educação e resistência. Revista Emcrise. Entrevista concedida em 27/07/2002 a André Deak, Lígia Ximenes e Rodrigo Savazoni. Disponível em < http:// www.andredeak.com.br/emcrise/entrevistas/entsobrinho. html>. Acesso em: 20/05/2011.

FLECK, M. P. A. et al. Desenvolvimento da versão em português do instrumento de avaliação de qualidade de vida da OMS (WHOQOL-100). Revista Brasileria de Psiquiatria, São Paulo, v. 21, n. 1, 1999.

FÓRUM DE PRÓ-REITORES DE EXTENSÃO DAS UNIVERSIDADES PÚBLICAS BRASILEIRAS. Indissociabilidade ensino-pesquisa-extensão e a flexibilização curricular: uma visão da extensão. Porto Alegre: UFRGS; Brasília: MEC/SESu. 2006. p.100. (Coleção Extensão Universitária).

FREIRE, P. Extensão ou comunicação? 7 ed. Rio de Janeiro: Paz e Terra, 1983. 93 p. (O Mundo, Hoje, v. 24).

LANDIS, J.R.; KOCH, G.G. The measurement of observer agreement for categorical data. Biometrics, v. 33, p. 159174, 1977.

MORIN, E. Ciência com consciência. 6 ed. Rio de Janeiro: Bertrand Brasil, 2002.

PEREIRA, J. C. R. Análise de dados qualitativos: estratégias metodológicas para as ciências da saúde humana e sociais. 3 ed. São Paulo: Edusp, 2001.

POPPER K. A lógica da pesquisa científica. São Paulo, Cultrix, 1993.

ROCHA, N. S.; FLECK, M. P. A. Validade da versão brasileira do WHOQOL-BREF em pacientes deprimidos usando o modelo de Rasch. Revista de Saúde Pública, São Paulo, v. 43, n. 1, p. 147-153, 2009.

SZWARCWALD, C. L.; DAMACENA, G. N. Amostras complexas em inquéritos populacionais: planejamento e implicações na análise estatística dos dados. Revista 
Brasileira de Epidemiologia. São Paulo, v. 11, supl. 1, p. 38-45, 2008.

OLIVEIRA, P. P. A construção social da masculinidade. Belo Horizonte: UFMG, 2004. 347 p.

VILLAR, G. B. Gênero, cuidado e saúde: estudo entre homens usuários da atenção primária em São Paulo. 2007. 191 f. Dissertação. (Mestrado em Ciências Medicina Preventiva) - Faculdade de Medicina, Universidade de Federal de São Paulo, UNIFESP, São Paulo.

WHO. WORLD HEALTH ORGANIZATION. Oral Health Survey: basic methods. 4 ed. Geneva: WHO, 1997.

Physical status: the use interpretation of antropometry. Report of a WHO expert committee. Geneva: WHO, 1995. (Technical Report Series 854).

Recebido em: 20/out/2011

Aceito em: 26/nov./2011 